\title{
BMJ Open Indigenous communities' responses to the COVID-19 pandemic and consequences for maternal and neonatal health in remote Peruvian Amazon: a qualitative study based on routine programme supervision
}

\author{
Stefan Reinders (D) , ${ }^{1}$ Angela Alva, ${ }^{1}$ Luis Huicho, ${ }^{2}$ Magaly M Blas ${ }^{1}$
}

To cite: Reinders S, Alva A, Huicho L, et al. Indigenous communities' responses to the COVID-19 pandemic and consequences for maternal and neonatal health in remote Peruvian Amazon: a qualitative study based on routine programme supervision. BMJ Open 2020;10:e044197. doi:10.1136/ bmjopen-2020-044197

- Prepublication history for this paper is available online. To view these files, please visit the journal online (http://dx.doi. org/10.1136/bmjopen-2020044197).

Received 25 August 2020 Revised 29 November 2020 Accepted 09 December 2020

Check for updates

(C) Author(s) (or their employer(s)) 2020. Re-use permitted under CC BY-NC. No commercial re-use. See rights and permissions. Published by BMJ.

For numbered affiliations see end of article.

Correspondence to Stefan Reinders; reinders.stefan@gmail.com

\section{ABSTRACT}

Aim To explore indigenous communities' responses to the COVID-19 pandemic and its consequences for maternal and neonatal health (MNH) care in the Peruvian Amazon.

Methods Mamás del Río is a community-based, MNH programme with comprehensive supervision covering monthly meetings with community health workers (CHW), community leaders and health facilities. With the onset of the lockdown, supervisors made telephone calls to discuss measures against COVID-19, governmental support, CHW activities in communities and provision of MNH care and COVID-19 preparedness at facilities. As part of the programme's ongoing mixed methods evaluation, we analysed written summaries of supervisor calls collected during the first 2 months of Peru's lockdown.

Results Between March and May 2020, supervisors held two rounds of calls with CHWs and leaders of 68 communities and staff from 17 facilities. Most communities banned entry of foreigners, but about half tolerated residents travelling to regional towns for trade and social support. While social events were forbidden, strict home isolation was only practised in a third of communities as conflicting with daily routine. By the end of April, first clusters of suspected cases were reported in communities. COVID-19 test kits, training and medical face masks were not available in most rural facilities. Six out of seven facilities suspended routine antenatal and postnatal consultations while two-thirds of CHWs resumed home visits to pregnant women and newborns.

Conclusions Home isolation was hardly feasible in the rural Amazon context and community isolation was undermined by lack of external supplies and social support. With sustained community transmission, promotion of basic hygiene and mask use becomes essential. To avoid devastating effects on MNH, routine services at facilities need to be urgently re-established alongside COVID-19 preparedness plans. Communitybased MNH programmes could offset detrimental indirect effects of the pandemic and provide an opportunity for local COVID-19 prevention and containment.
Strengths and limitations of this study

- In this qualitative study we analysed data collected through routine programme supervision-an approach with methodological shortcomings in comparison to traditional qualitative study designs.

- No formal interviews were conducted; instead, supervisors enquired about COVID-19-related themes during their telephone-based, routine supervision meetings.

- Conversations during supervisory meetings were not audio recorded; instead, written conversation summaries were analysed descriptively which did not allow in-depth exploration of perceptions, attitudes or beliefs.

- Quantification of themes was attempted as data are based on a sample largely representative of the three districts; however, a suboptimal response rate and lack of systematic probing of subthemes might have affected accuracy of some estimates.

- Our alternative approach provided a unique opportunity to timely capture the response of indigenous communities to COVID-19 and its impact on maternal and neonatal health in the early phase of a rapidly developing international emergency.

\section{BACKGROUND}

In December 2019, a cluster of pneumonia caused by a novel coronavirus (SARS-CoV-2) emerged in Wuhan. By the end of June 2020, the virus had spread to almost 200 countries, infecting more than 10 million people and causing more than 500000 deaths worldwide. ${ }^{1}$ With no available treatment or vaccination, most governments responded with confinement, closure and lockdown to suppress the spread of the virus and to alleviate strain on health systems. ${ }^{2}$

Such a lockdown was unprecedented, with 4.5 billion people worldwide being subject to 
home isolation by mid-April. ${ }^{3}$ While lockdown measures were found effective in reducing community transmission in China and Europe, ${ }^{4-7}$ effectiveness is likely context dependent. Transmission patterns are modified by population density, social mixing behaviour and environmental factors, ${ }^{8}$ while health impact is determined by age, underlying nutrition status, comorbidities and healthcare capacity. ${ }^{9}$ Trajectories of the pandemic are therefore different across countries and settings. Lockdown measures are associated with substantial socioeconomic and health consequences ${ }^{10}{ }^{11}$ that potentially offset benefits of disease containment, ${ }^{12}$ resulting in a debate on the appropriateness and applicability of such measures, especially in low and middle-income countries (LMICs). ${ }^{13}$

The Peruvian government was one of the first in Latin America to declare a national emergency and measures taken were among the strictest worldwide (figure 1) ${ }^{2}$ From mid-March 2020, lockdown measures included immediate closure of all borders, a police and military-enforced home isolation, prohibition of non-essential business and domestic travel, a night curfew and school closures. ${ }^{14}$ In early April, mask use in public became mandatory ${ }^{15}$ and testing capacity was drastically increased. ${ }^{16}$ While Peru has one of the highest testing rates in Latin America, ${ }^{17}$ mostly IgM/IgG antibody tests are employed ${ }^{18}$ that have limited value to detect acute infections. Economic support covered initially urban households and was subsequently extended to rural households. ${ }^{19-22}$ Mounting economic pressure led to reactivation of the economy and gradual easing from May onwards, ${ }^{23}$ with home isolation officially lifted in most regions of Peru by early July. Despite these measures, incidence of confirmed cases gradually increased, peaking in early June and subsequently stabilising at a high level (figure 1). Cases per million population exceeded 8500 by end of June, rendering Peru one of the most affected countries worldwide. ${ }^{24}$

While the outbreak was initially confined to metropolitan Lima, it eventually spread to all regions and reached rural and remote areas by May. ${ }^{25}$ In Peru, people of native ethnicity comprise about a quarter of the population, predominantly living in the rural Andes or the Amazon jungle. ${ }^{26}$ In these regions, about half of the population lives below the poverty line ${ }^{27}$ and does not have access to running water. ${ }^{28}$ Although improvements have been achieved in recent years, coverage of healthcare services is still unequal and maternal and neonatal health (MNH) indicators lag behind ${ }^{29}$ Despite a favourable demographic profile due to younger age, food insecurity, household overcrowding and lack of access to basic health services could render indigenous populations at increased risk for direct health effects of COVID-19. Indirect effects of the pandemic through disruption of health services, as seen around the world, ${ }^{30}$ could threaten improvements in $\mathrm{MNH}$ in Peru. ${ }^{29} 31$

To provide context-specific solutions, ${ }^{8}$ there is a need to better understand responses to and impact of COVID-19 in hard-to-reach regions and indigenous communities. ${ }^{32}$ The authors capitalise on data collected during routine supervision and monitoring of a community-based MNH programme to uniquely capture the communities' response to COVID-19 and the impact of the pandemic on $\mathrm{MNH}$ care in the remote Peruvian Amazon during the first 2 months of the country's lockdown.

\section{METHODS}

\section{Setting and programmatic background}

Loreto is located in the north Amazon jungle of Peru (figure 2). Half of its population is concentrated in the capital (Iquitos) and about a third live in remote rural areas $^{26}$ along the extensive Amazon river systems. Loreto is one of the departments with the poorest MNH indicators in Peru, with 2012 estimates suggesting a neonatal mortality rate of 19 per 1000 live births ${ }^{31}$ and $55 \%$ of neonatal mortality under registration. ${ }^{33}$ In some rural

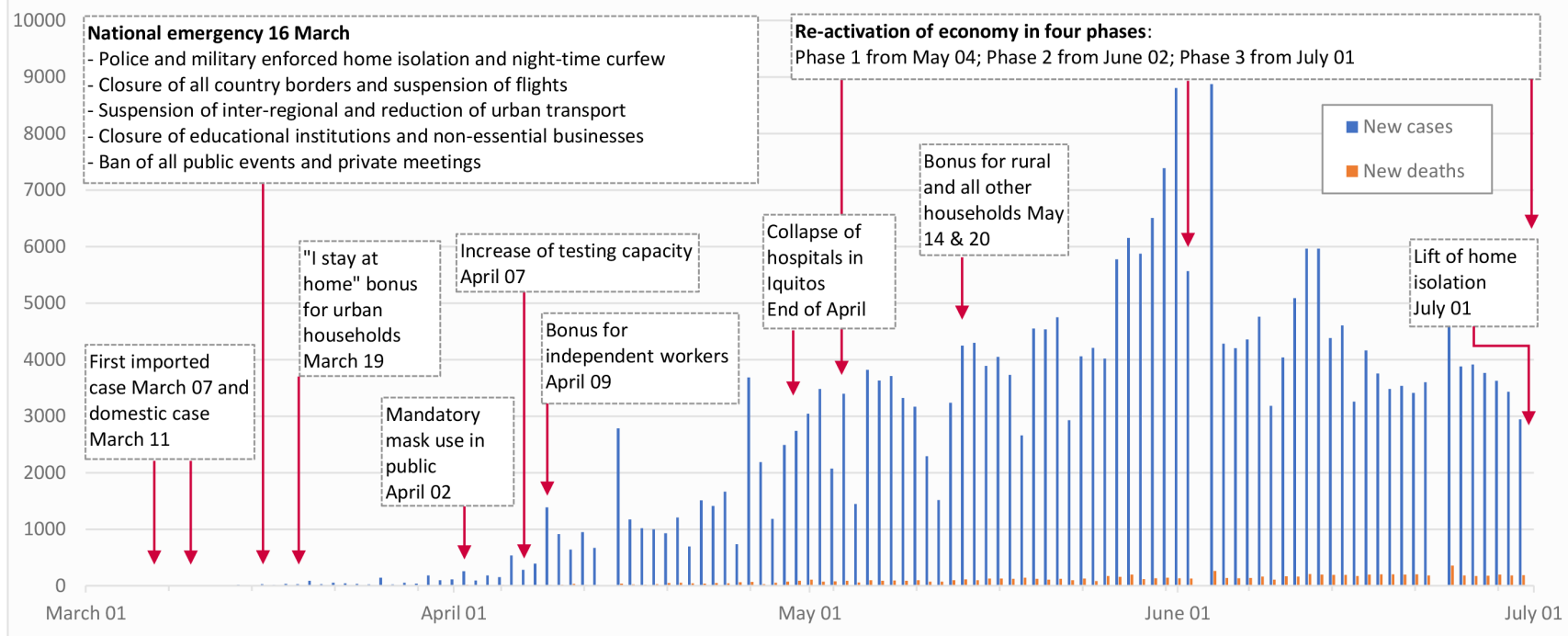

Figure 1 Timeline of governmental response and epidemiology of COVID-19 in Peru, March to June $2020 .^{24}$ 


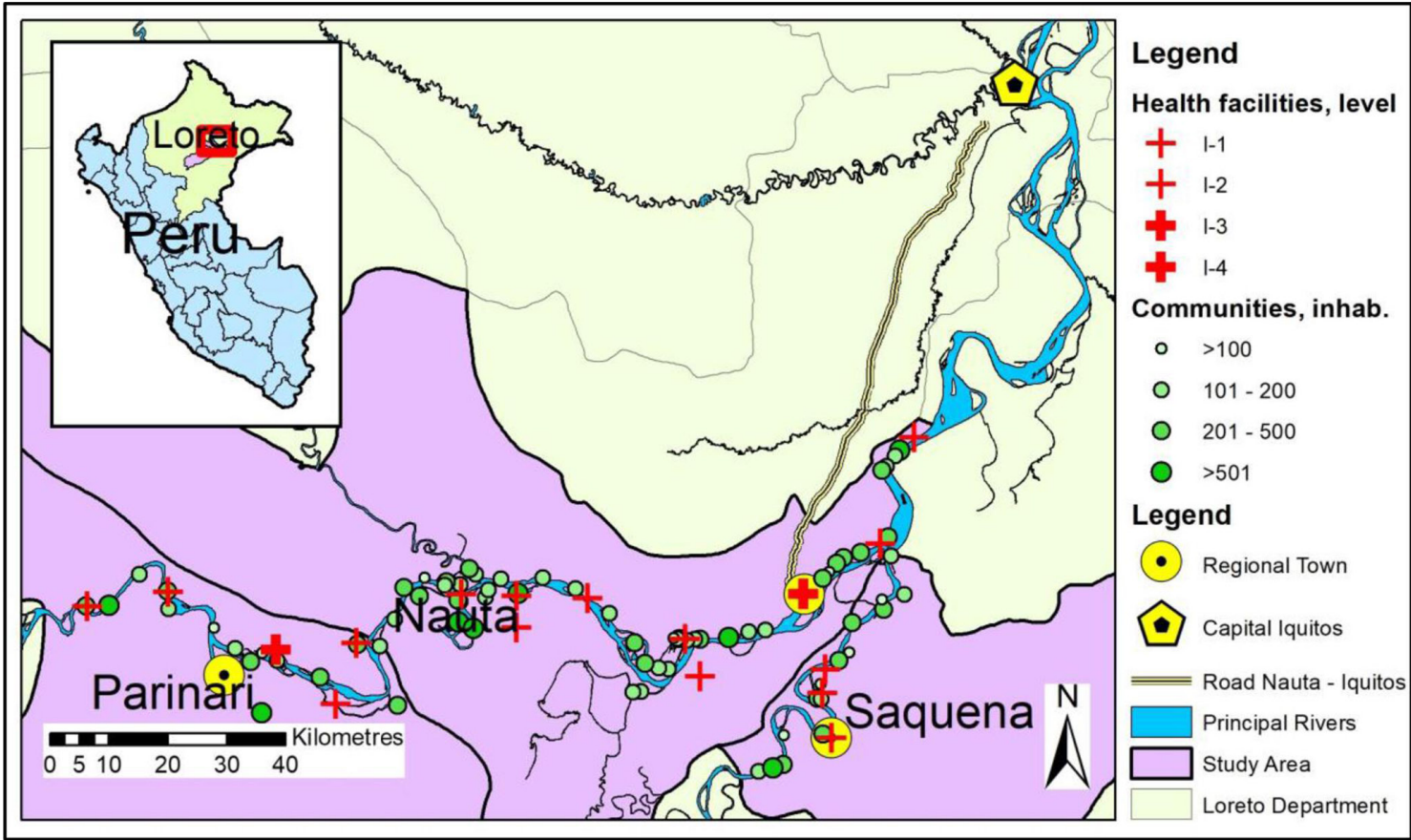

Figure 2 Mamás del Río programme implementation area (own assembly).

communities $80 \%$ of women give birth at home ${ }^{34}$ and infection remains a leading cause of neonatal deaths. ${ }^{35}$

Mamás del Río (MDR) is an MNH programme operating in remote rural Amazon areas, aiming to improve essential newborn care (ENC) practices and neonatal healthcare seeking through educational home visits by community health workers (CHW, Agentes Comunitarios de Salud) to pregnant women and mothers with newborns. Supportive programme components include training of traditional birth attendants (TBA, parteras tradicionales), strengthening of healthcare facilities and comprehensive supervision.
A 2-year programme evaluation with repeated household censuses and an in-depth mixed methods process evaluation is currently undertaken within a wellcharacterised study area. MDR is implemented in the rural areas of three districts (Nauta, Parinari, Saquena) in Loreto, covering 79 predominantly native communities of Kokama-Kokamilla ethnicity with a population of 14474 , almost half $(44 \%)$ between 0 and 14 years old and $10 \%$ above 60 years of age. Communities are physically separated settlements dispersed along $350 \mathrm{~km}$ of the Amazon river or its subsidiaries (figure 2) within dense tropical rainforest and difficult access by boat only. Villagers live

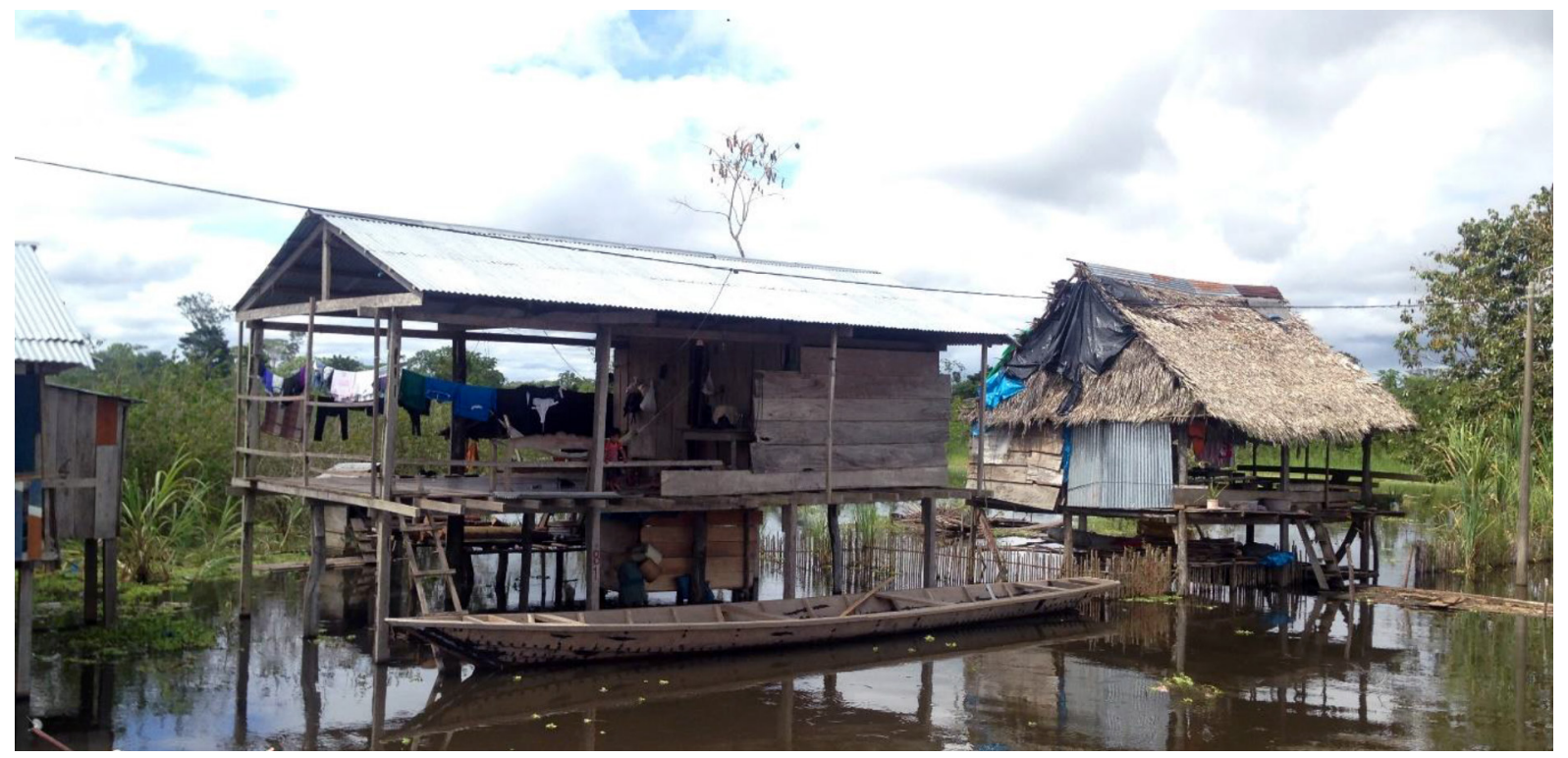

Figure 3 Wooden housing in the Peruvian Amazon during high river levels (photo credit: Stefan Reinders, 2017). 
Table 1 Demographic and household characteristics, and uptake of maternal care of women aged 15-49 years with a live birth in the last 12 months $^{*}(n=324)$

\begin{tabular}{|c|c|c|}
\hline & $\mathbf{n}$ & $\%$ \\
\hline \multicolumn{3}{|l|}{ Age (years) } \\
\hline $15-24$ & 121 & 37 \\
\hline $25-34$ & 138 & 43 \\
\hline $35-49$ & 65 & 20 \\
\hline \multicolumn{3}{|l|}{ Highest education† } \\
\hline None/preschool & 3 & 1 \\
\hline Primary & 163 & 50 \\
\hline Secondary & 149 & 46 \\
\hline Higher education & 7 & 2 \\
\hline \multicolumn{3}{|l|}{ Household income† } \\
\hline$<150$ soles $(\sim$ US $\$ 42)$ & 167 & 52 \\
\hline $151-300$ soles & 129 & 40 \\
\hline$>300$ soles ( US\$84) & 26 & 8 \\
\hline \multicolumn{3}{|l|}{ Primary water source of household } \\
\hline River or spring & 158 & 49 \\
\hline Public tap or well & 79 & 24 \\
\hline Private well or rainwater from roof & 69 & 21 \\
\hline Other & 18 & 6 \\
\hline Piped into dwelling & 0 & 0 \\
\hline \multicolumn{3}{|l|}{ Number of facility ANC consultations $\ddagger$} \\
\hline 0 visit & 26 & 8.0 \\
\hline $1-5$ visits & 110 & 34.0 \\
\hline $6-7$ visits & 104 & 32.1 \\
\hline$\geq 8$ visits & 84 & 25.6 \\
\hline \multicolumn{3}{|l|}{ Place of birth } \\
\hline Health facility & 114 & 35 \\
\hline Home birth & 208 & 64 \\
\hline Other & 2 & 1 \\
\hline \multicolumn{3}{|l|}{ Caesarean section } \\
\hline Yes & 25 & 8 \\
\hline
\end{tabular}

*Women were identified based on a census of all communities in the Mamás del Río (MDR) implementation area conducted in early 2019 as part of the programme evaluation.

†Two women answered 'don't know'. fOne woman answered 'don't know'.

ANC, antenatal care.

in wooden huts on stilts due to frequent flooding in the rainy season (figure 3). Main occupation is subsistence farming and fishing.

Each community is self-governed by a community leader $(A p u)$ and a governor (Teniente), who convene community assemblies for decision-making. Most communities have a CHW and a traditional healer, who are consulted for health issues. Data from questionnaires to women with a live birth in the last year, collected as part of a baseline census conducted in early 2019, show that poor education and extreme poverty are prevalent (table 1). Most women give birth at home and more than one-third do not receive six antenatal care (ANC) consultations at a health facility, as recommended nationally. ${ }^{36}$

In Peru, a basic insurance scheme (Seguro Integral de Salud) covers free access to public medical care and medication. The MDR implementation area comprises 18 health posts and three health centres. Two-thirds of the communities are within $4-17 \mathrm{~km}$ distance to a health facility ( $20 \mathrm{~min}$ to 1.5 hours of travel by motorised canoe). All health facilities provide routine antenatal and postnatal care as well as emergency and imminent birth care. However, half of health posts are only staffed by a nurse technician, are poorly equipped and often lack basic infrastructure such as running water and electricity, based on our own inspection. The nearest hospital is located in Iquitos city. Access is difficult and requires boat travel to the regional town of Nauta and a subsequent 2-hour drive to Iquitos.

As part of the MDR programme implementation, communities were invited to select a volunteer CHW to participate in a 5-day training workshop to learn to administer pregnancy tests and perform three home visits during pregnancy and three within the first week after birth. Aided by electronic tablets, CHWs develop a birth and emergency plan, promote ANC seeking and institutional delivery, ask for danger signs or complications, distribute clean birth kits and promote ENC if facility birth is not feasible or desired. After birth, they weigh and refer the newborn in case of very low birth weight or other complications and promote ENC including early newborn control at a facility. Of 77 CHWs initially trained, most were middle-aged men and only a quarter had secondary education. About two-thirds had previous experience as health promoters (promotores de salud), with inconsistent governmental training mostly focused on treatment of diseases.

The MDR programme has a comprehensive supervision and monitoring component. A team of four supervisors (female and male nurse technicians) and one local coordinator (female graduated nurse) conduct monthly in-person supervisory visits to all communities participating in the programme. Since the start of the programme in early 2019, they have provided ongoing support, training and materials and maintained a close working relationship with the CHWs. During community visits, supervisors also meet with community leaders, TBAs and facility staff to identify and solve emerging problems related to the work of the CHWs, programme operation and MNH care. Supervisors do not have formal interviewer training.

\section{Study design and participant selection}

One substudy of the programme's ongoing mixed methods evaluation is the collection and analysis of written supervisor reports obtained during routine supervision activities. The present study features an analysis of written summaries of supervisor meetings with the 
programme's stakeholders that were collected during the first 2 months of Peru's lockdown, allowing to capture insights into the communities' response to COVID-19 and the pandemic's direct and indirect impacts on MNH care. The underlying sample constitutes one CHW and one community leader from all rural communities as well as one staff member from all health facilities of the three districts within which the programme is operating.

\section{Data collection}

After the start of the lockdown, in-person visits were not feasible anymore and the programme directors (MMB and SR) instructed the supervision team to make phone calls for conversations with community leaders, CHWs and health staff as part of their routine supervision meetings. This was possible since supervisors had established directories of phone contacts during their prior continuous engagement in communities. Conducting 'televisits' allowed gaining valuable insights remotely while resuming some of the usual supervision and monitoring activities, such as checking stock of materials, performance of CHWs and problem solving. To guide supervisors, we updated their work manual with procedures for telephone follow-up and immediate COVID-19 prevention measures to share. The manual's conversation guide was complemented with COVID-19-related topics to cover open-ended questions with probes on: (1) measures taken against COVID-19 at the personal and community levels; (2) presence and management of suspected cases, (3) availability and access to routine antenatal, delivery, postnatal and general emergency care; and (4) impact on CHW's routine activities. The receipt of governmental emergency supplies and economic aids was evaluated during a second round of supervisory calls 2 weeks later.

The programme coordinator (AA) and the local coordinator called one member of staff involved in MNH care at each facility in the area and asked open-ended questions on: (1) availability of routine antenatal, delivery, and postnatal care and general emergency services; (2) reasons for possible service suspension; and (3) COVID19-related access barriers to services. In a second round of calls 1 month later, the same questions were repeated and COVID-19 preparedness was discussed additionally, including receipt of personal protective equipment (PPE), testing kits and training materials.

Supervisors and coordinators wrote a summary after each call, thematically structured as per the conversation guide. They attempted to reach actors at different times and days, calling all numbers available, to maximise contact likelihood. A community or facility was considered uncommunicable after a maximum of 10 attempts.

\section{Data analysis}

We analysed written summaries in the original language in Spanish using a framework approach, ${ }^{37}$ chosen as it is most useful for managing and mapping of large data sets. We defined categories a priori as per questions in the conversation guide and complemented the framework inductively and in an iterative manner with newly emerging themes. SR and AA used an Excel spreadsheet as a matrix to chart and analyse descriptive-level data according to themes arranged in columns, which were subsequently compared across communities arranged in rows. Since the sample was largely representative of three districts and supervisors consistently used conversation guides, occurrence of principal themes and subthemes was counted across all communities to allow quantification. Information obtained by CHWs and leaders from the same community was triangulated and, unless conflicting, summarised for each community (ie, community actors). The same procedure was repeated for data obtained from facility staff. Data provided by community actors on facility services were triangulated with data obtained from health staff. The main results were validated directly with the supervisors and any inconsistencies were resolved. Translation from Spanish to English emphasising conceptual equivalents was done by SR who is proficient in both languages. The resulting framework combining themes related to communities and facilities is shown in box 1 . To discuss the impact on MNH care, we refer to an adapted health systems framework, ${ }^{38}$ postulating that four components (availability of health workers, availability of supplies and equipment, demand for health services and access to health services) determine the provision, utilisation and, ultimately, coverage of health services.

\section{Patient and public involvement}

Patients and/or the public were not involved in the design, conduct, reporting or dissemination plans of this research.

\section{RESULTS}

During the first round of calls between 8 and 21 April 2020, 68 out of 84 communities were contacted. Conversations were held with both the CHW and the community leader in $65 \%$, and with the CHW or leader only in $31 \%$ and $4 \%$ of the cases, respectively. Calls lasted from 45 to $60 \mathrm{~min}$. During the second round of calls between 30 April and 5 May 2020, 57 communities were contacted, of which 54 had been contacted in the first round. Each call lasted for about $15 \mathrm{~min}$. Health facilities were first called between 27 March and 1 April 2020, and 17 out of 21 were contacted, calls lasted about $15 \mathrm{~min}$. During a second round of calls between 1 and 9 May 2020, 14 out of 21 facilities were reached. All but one health facility had been contacted in the first round.

\section{Measures against COVID-19 in communities}

All contacted CHWs and leaders stated that their communities complied with governmental measures against COVID-19. Probing, however, revealed that the scope of implemented measures was very heterogeneous, comprising different combinations of community isolation, social distancing within communities and individual prevention measures. 
Box 1 Charting and analysis framework with principal categories, themes and subthemes

Measures against COVID-19 at community level
- Entry restrictions
- Ban to enter community
- Guarding of ports by villager groups
- Exceptions to enter community
Exit restrictions
- Ban to leave community
- Exceptional permissions to leave community
Social distancing within community
- Ban of agglomerations
- Movement restrictions
- Enforcement of orders
Individual prevention measures
- Bathing and washing on return to community
- Preventative medications
- Use of face masks
Suspected cases of CoVID-19 and their management
Cases with COVID-19 compatible symptoms
Treatment and healthcare seeking of suspected cases
External support to communities
- Emergency food packages
- Coverage and content
- Conditional delivery
- Healthcare seeking
- Economic support
- 'I stay at home' emergency economic support
- Governmental social programmes
Availability of and access to healthcare
- Community-based health promotion
- Visits by health brigades for COVID-19
- Mampact on community health worker (CHW) home visits as part of
- SuDR) programme
-

\section{Community isolation}

Almost all communities (59/68) instigated rules prohibiting entry of non-residents, including family members. About half (30/68) established rotating groups of villagers guarding the port or community entry; some reported barricading smaller river channels with canoes or putting up signs 'ENTRY FORBIDDEN TO FOREIGNERS'. Only a few communities made exceptions to this rule, in case of emergencies or when receiving produce from neighbouring communities. Only few actors $(13 / 68)$ stated that their residents were prohibited from leaving. In about half of communities $(30 / 68)$, the actors stated or indirectly implied that residents were tolerated or allowed to leave the community. Some explicitly noted that they depend on farming and fishing, and need to travel to the regional town to sell their produce or to claim governmental cash incentives. Others sent small envoys for collective purchase of supplies in the regional town. On two occasions, returning villagers were required to be quarantined for 7 and 14 days, respectively.

\section{Social distancing within communities}

More than half of all communities (40/68) had measures in place to reduce crowds and physical contact among villagers. Most commonly, sports and recreational activities including volleyball, football or bingo were banned. Church services were often forbidden and some banned public assemblies.

Movement restrictions within the community were reported in about a third (27/68) of communities; a night-time curfew was most common. Daytime home isolation as mandated by the government was also enforced but usually with specific time windows to allow villagers leaving the house and performing essential activities such as water gathering, bathing, farming, fishing or buying food. In a few communities, daily activities resumed without restrictions in the absence of cases.

Some communities with stricter social distancing measures also had designated surveillance teams patrolling the community to assure people abide local orders. A few communities imposed punishments for those breaking the rules, such as being locked away temporarily, obliged to do community work or being reported to the local police.

\section{Individual prevention measures}

About a quarter $(16 / 68)$ of communities had orders in place requiring villagers to bath and wash themselves thoroughly when re-entering the community, especially after visiting other communities or regional towns. In two cases, villagers had to undergo disinfection by highpressure cleaners with a solution containing detergent and bleach.

Only one-fifth $(18 / 68)$ of communities mentioned use of face masks. Mostly, villagers were required to use masks when leaving for regional towns, whereas in only three communities their use was mandatory. One community produced their own masks; in another, health staff was reportedly selling them.

\section{Suspected cases of COVID-19 and their management}

During the first round of calls, three communities reported villagers with COVID-19 symptoms and travel history to a regional town or contact with a confirmed case. The director of a primary school was considered a suspected case and denied entry to the community after his daughter had tested positive. The second suspected case was a woman who was required to isolate and get tested after rumours emerged that one of her clients, whom she sold fish during a visit to the regional town, had tested positive for COVID-19. The third suspected case was a man in his 40 s who presented with cough and difficulty breathing after returning from the regional town. He received a cocktail of lemon, garlic, ginger and onion, and a plant-based vapour from the community's healer. After symptoms worsened, he was referred to the 
nearby health post by the CHW but was denied entry to the community.

After the second round of calls, CHWs of seven communities reported clusters of persons with symptoms including high fever, dry cough and/or difficulty breathing. Travel history was only documented in one case. Interestingly, although no formal diagnosis was made to confirm or rule out COVID-19, most CHWs emphasised that these were cases of severe influenza. They were treated with plant-based remedies and did not seek help at facilities.

\section{External support to communities}

Inconsistent coverage of governmental emergency food supplies, reported during the first round of calls, prompted us to systematically evaluate the receipt of supplies since the start of the lockdown. By early May, all but one community had received one delivery of food bundles containing rice, noodles, milk, oats and sugar. In Saquena, all families, except those from one community, received supplies. This was not the case in about half of the communities in Parinari and most of Nauta communities. Community actors reported that families were exempt from food supplies if they were listed as beneficiaries of governmental social programmes targeted at families below the poverty threshold. Among 20 affected communities that provided number of recipients, only one-third of all families reportedly benefited. No other external support was received by communities.

The governmental COVID-19 economic bonus 'I stay at home' initially targeted urban areas and was therefore claimed only by a few villagers with a registered address in a regional town. Irrespective of community isolation measures and lack of public transport due to the lockdown, beneficiaries of the social programmes JUNTOS and Pension 65 from more than half of communities $(36 / 68)$ found ways to claim their benefits in regional towns. To claim benefits of JUNTOS, a cash transfer programme targeted at poor families with children under 5 years, some communities organised committees and asked schoolteachers or health staff to claim the benefit on their behalf to avoid travel. Pension 65, a programme supporting poor pensioners above 65 years, required beneficiaries to personally claim the benefit in regional towns.

\section{Availability and access to healthcare \\ Community-based health promotion}

Although all communities were aware of the COVID-19 emergency, during the first round of calls participants of only six communities reported the receipt of external COVID-19-related health promotion. In these cases, a visiting brigade of health centre staff and other institutions held town hall talks and distributed educational flyers. Two communities received COVID-19-related information from indigenous federations, while two CHWs reported they were holding talks on coronavirus and promoted hand washing.
Local rules allowed CHWs to continue with their usual activities as part of the MDR programme in two-thirds $(46 / 68)$ of all communities. A few CHWs mentioned that while they were allowed to perform home visits, the decision to receive the visit or not remained with the woman and her family. Since the last supervisory visit in March, contacted CHWs administered 79 pregnancy tests, registered 17 pregnant women, conducted 64 home visits and distributed 19 clean birth kits. Four of every five CHWs had satisfactory stock levels of materials.

\section{Facility-based antenatal, postnatal and delivery care}

During the first round of calls to facility staff, $65 \%$ $(11 / 17)$ of facilities contacted (nine health posts and two health centres) had suspended antenatal and postnatal routine consultations and only attended emergencies and imminent births. While staff from all facilities in Saquena followed an order from the subregional directorate to suspend routine services to avoid crowding, staff of half the facilities in Nauta and Parinari had not received such orders, but decided themselves to suspend services for personal protection. During the second round of calls, the proportion of facilities that ceased to offer routine MNH services increased to $85 \%$ (12/14 contacted). Staff from one facility explained they were afraid of contracting COVID-19, after the recent arrival of symptomatic persons from the capital Iquitos and lack of PPE and COVID-19 test kits.

Triangulation of information obtained by facility staff with information from community actors was possible for eight facilities and corroborated findings of severe disruptions in antenatal and postnatal routine services. Furthermore, CHWs complained that services of facilities that did not suspend routine $\mathrm{MNH}$ care were only accessible to residents of the same community, given the entry restrictions. Except for one community, entry to communities and corresponding health facilities was only permitted in case of emergencies. This, however, required prior arrangement and compliance with local rules, which could act as a further hurdle. In one case, a nurse technician referred a patient with acute hypertension to a health centre, but was refused entry to the community since the patient did not wear mask.

\section{COVID-19 preparedness in facilities}

Health facilities were all equipped with basic PPE, including surgical masks, gloves, coats, caps and boots. Only three facilities had N95 face masks available, which had to be reused due to very limited supply. Goggles or face shields were not available at any facility. Only 2 of 14 facilities contacted had received any formal training or educational materials on COVID-19; most obtained information from the internet or television on their own initiative.

SARS-CoV-2 test kits were not available, except in the referral health centre in Nauta. To get tested, suspected cases had to travel to the regional town. Staff also provided insights on healthcare seeking for COVID-19. One health 
post staff noted that despite having issued a referral, suspected cases were reluctant to travel to Nauta and decided to treat their symptoms with natural remedies in the community. Health centre staff from Nauta explained that confirmed cases with mild to moderate symptoms were brought to a designated isolation centre outside of town, whereas severe cases were referred to Iquitos. A police checkpoint had been set up at the entrance of Nauta to screen persons for symptoms who would then either be sent to the isolation centre or obliged to undergo 1 week of quarantine.

\section{DISCUSSION}

The COVID-19 pandemic in Peru is highly dynamic and fast moving. By the time of the write-up of this paper, two further rounds of calls suggested that COVID-19 had taken full hold of communities. By the end of June, almost all communities contacted reported clusters of suspected cases or large outbreaks, suggesting transition to community transmission. About a quarter of communities reported confirmed cases after testing by visiting health brigades. Triangulation of our data with official case and death counts of the health ministry suggests substantial under-reporting, as observed elsewhere. ${ }^{25}$ Official statistics captured seven confirmed cases for Saquena and Parinari until the end of June $2020^{39}$ while multiple confirmed cases were reported by 13 communities in the same period. Fifteen COVID-19-related deaths were reported by contacted communities in Nauta; however, only three deaths for the entire district of Nauta, including the capital with a population of about 20000 inhabitants, appeared in official statistics.

All native communities contacted had measures in place to respond to COVID-19, but we observed considerable variation in coverage and composition. Our findings indicate that home isolation as mandated by the government was only inconsistently implemented. This is not surprising, as three-quarters of households source their water from the river or public wells. People bath mostly in rivers and primary income-generating activities require leaving the house multiple times a day. Strict home isolation is therefore hardly feasible in the rural Amazon setting, in line with findings that nationwide home isolation policies in LMICs conflict with realities of daily life. ${ }^{4041}$

In early April, the national organisation representing local indigenous federations in the Peruvian Amazon called for complete isolation of communities and a 14-day quarantine for any person entering the community from cities, as part of a plan against COVID- $19 .{ }^{42}$ We found that almost all communities banned the entry of foreigners; however, most communities tolerated residents to travel to larger towns to purchase supplies, sell produce or claim social support. Since strict home quarantine on return was seldom reported, returning villagers most likely presented the entry corridor for COVID-19 to rural communities, especially after visiting crowded urban markets identified as infection hotspots in Peru. ${ }^{434}$ To make strict community isolation feasible, regular delivery of governmental supplies with universal coverage of residents and local access to social support is required to discourage travel to urban areas. Points to claim cash incentives from social programmes need to be implemented in rural areas, or the claiming process needs flexibility to avoid exposing risk groups, as it was seen with the elderly who had no alternative as to claim their pension in person. The economic bonus for rural households activated in mid-May, ${ }^{22}$ at a time when the outbreak peaked in Iquitos, might have caused further unintentional spread of the virus from urban to rural areas, as it required travel to urban branches of the Peruvian national bank.

Use of face masks was not common in communities, despite mandatory use in public was compulsory from early April. ${ }^{15}$ While we did not systematically probe for availability of face masks, a shortage in such remote communities is highly plausible, as it was the case in Peru and other countries during that period. ${ }^{45}$ The principal route of transmission of COVID-19 is via respiratory droplets during close contact, ${ }^{46}$ and the WHO recommends use of non-medical masks in settings with COVID-19 community transmission. ${ }^{47}$ In the context of rural communities where strict home and community isolation is not feasible, and given the sustained community transmission currently observed, mask use should be promoted and their supply externally guaranteed or local production incentivised.

We found substantial disruption to provision of routine MNH care; only 1 in 7 health facilities continued to offer antenatal and postnatal care. Surprisingly, some staff suspended services on orders by the regional health authority, despite the existence of a ministerial resolution mandating continuity of sexual and reproductive health services in emergency situations. ${ }^{48}$ Staff also suspended services on their own account to protect themselves, which is not surprising, given the absence of COVID-19 test kits, insufficient stock of PPE and lack of training identified. The widespread practice of community entry bans further reduced access for women seeking routine services at facilities outside their own community. Although all facilities continued to attend emergencies and imminent births, community isolation, lack of public transport and fear of infection most likely discouraged facility births and early care seeking for obstetric emergencies.

Observed disruptions, coupled with access restrictions and lower demand, risk reducing the coverage of essential interventions delivered during antenatal, delivery and postnatal care. As seen during the Ebola epidemic in Sierra Leone, reductions in use of essential MNH care rendered the indirect effects of Ebola on maternal and neonatal mortality as high as the direct effects. ${ }^{49}$ Authors of a recent modelling study estimate that coverage reductions in antenatal, childbirth, postnatal and early child care and increase in wasting over 6 months as indirect effects of the COVID-19 pandemic could result in 1157000 additional child deaths and 56700 additional maternal deaths in all 
LMICs combined, in the worst scenario. ${ }^{38}$ Our groundlevel insights provide early support to assumptions made in modelling studies ${ }^{3850}$ and show that coverage reductions are not merely hypothetical but real. We therefore echo the global call urging policymakers and local authorities to restore provision of routine MNH services to protect hard-won gains achieved in the last decades. ${ }^{30}$ In line with findings from a recent global online survey among MNH care providers, ${ }^{51}$ we found poor COVID-19 preparedness in rural facilities. Ensuring implementation of COVID-19 plans, which could be based on existing guidance by international agencies, ${ }^{52}$ is a prerequisite for achieving this goal.

The COVID-19 pandemic has exposed the shortcomings of centralised containment measures that disregard the unique characteristics and challenges posed by the pandemic among remote indigenous communities. Collaborative and community-based efforts for COVID-19 prevention and containment could present a promising alternative approach to confront a disease with such powerful transmission dynamics. In the Bolivian Amazon, an initiative by scientists, community leaders and local government developed and implemented a multiphase plan among the Tsimane population with a focus on education and voluntary collective isolation at community level, followed by local case reporting and isolation, contact tracing and patient management. ${ }^{53}$ Reluctance of institutional healthcare seeking by suspected COVID-19 cases, likely incited by lack of preparedness at facilities, fears of being kept in isolation away from family and rumours of infected staff, further reinforce the need for local approaches. Initiatives like the MDR programme could leverage existing capacities and infrastructure at the community level ${ }^{54}$ and play an important role in planning and implementation of COVID-19 prevention and containment plans while simultaneously offsetting at least some of the detrimental indirect effects on $\mathrm{MNH}$.

We learnt valuable lessons during the application of alternative tools at the beginning of the COVID-19 pandemic to continue the supervision and monitoring activities of the MDR programme. Using phone calls, we were able to rapidly communicate with most communities in the programme's implementation area to provide initial information on COVID-19. During a time where in-person data collection was not feasible, we gathered information remotely through a pre-existing supervision and monitoring system which was used to inform regional authorities, understand communities' needs and prepare an immediate delivery of educational materials and supplies for COVID-19 prevention to communities. CHWs were trained and equipped to minimise COVID-19 infection risk during their home visits. It was encouraging to see that despite the difficult situation, many CHWs were able to continue with their activities as reflected in distribution of pregnancy tests and clean birth kits during home visits, although at lower levels than before the start of the pandemic. TBAs play an essential role in communitybased MNH as they attended every second home birth.
We will explore the impact on the work of TBAs during lockdown and further examine the impact of COVID-19 on coverage of essential $\mathrm{MNH}$ care during the upcoming follow-up census and qualitative work that is part of the programme's outcome and process evaluation.

The study has several limitations. Data were collected by supervisors with no formal interviewer training during their routine supervision activities. Conversations were not audio recorded and no verbatim transcriptions of conversations were available. Findings are based on highly aggregated, indirect testimonies of stakeholders and therefore quotes were not used. Analysis was descriptive; exploration of perceptions, attitudes or beliefs needs to be explored in further investigations. Quantifications of individual measures in communities such as use of face masks or quarantine are likely underestimated as not systematically probed for; however, we believe to have provided a complete account of communities' response to COVID-19 as well as status of MNH care services.

In conclusion, we found that home isolation, a principal component of centrally planned lockdown measures, was hardly feasible in the Amazon context. Lack of external provision of supplies and local availability of social support has undermined community isolation. In the context of sustained community transmission, promotion of basic hygiene and enabling universal mask use is essential. We observed drastic disruptions in routine maternal and neonatal services that need to be re-established, alongside facility-based preparedness and response plans for COVID-19, to avoid devastating effects on MNH. CHWbased programmes like MDR could offset some of the detrimental effects and provide an opportunity to implement community-based prevention and containment plans for COVID-19.

\section{Author affiliations}

${ }^{1}$ Epidemiology, STD and HIV Unit, School of Public Health and Administration, Universidad Peruana Cayetano Heredia, Lima, Peru

${ }^{2}$ Centro de Investigación en Salud Materna e Infantil, Centro de Investigación para el Desarrollo Integral y Sostenible, Facultad de Medicina, Universidad Peruana Cayetano Heredia, Lima, Peru

Correction notice This article has been corrected since it first published. The provenance and peer review statement has been included.

Acknowledgements We would like to thank all CHWs who are volunteering to improve the health of their community, even in these difficult times. We thank the supervisors who worked hard to collect the data. We would like to acknowledge Carine Ronsmans and Isabelle Lange from the London School of Hygiene and Tropical Medicine for their thoughtful comments which greatly improved the manuscript.

Contributors MMB and SR conceived the study. SR, AA and MMB contributed to the study design. SR and AA implemented and supervised the study execution and analysed the data. SR developed the first draft of the manuscript. SR, LH and MMB interpreted the data. All authors critically reviewed and gave final approval to the manuscript.

Funding The MDR programme's implementation and evaluation is funded by the National Council of Science and Technology (grant number 135-2016) and Grand Challenges Canada (grant number 0816-05).

Disclaimer The funders had no role in study design, data collection and analysis, decision to publish, or preparation of the manuscript. 
Map disclaimer The depiction of boundaries on this map does not imply the expression of any opinion whatsoever on the part of BMJ (or any member of its group) concerning the legal status of any country, territory, jurisdiction or area or of its authorities. This map is provided without any warranty of any kind, either express or implied.

\section{Competing interests None declared.}

Patient and public involvement Patients and/or the public were not involved in the design, or conduct, or reporting, or dissemination plans of this research.

\section{Patient consent for publication Not required.}

Ethics approval Ethical approval for the evaluation of the Mamás del Río programme was obtained from Cayetano Heredia Peruvian University (UPCH/100419) and included analyses of reports related to barriers and facilitators of programme operations collected as part of the routine supervision meetings with community health workers, leaders and health staff. Separate informed consent was therefore not required.

Provenance and peer review Not commissioned; externally peer reviewed.

Data availability statement De-identified supervisor reports are available from the corresponding author upon reasonable request.

Open access This is an open access article distributed in accordance with the Creative Commons Attribution Non Commercial (CC BY-NC 4.0) license, which permits others to distribute, remix, adapt, build upon this work non-commercially, and license their derivative works on different terms, provided the original work is properly cited, appropriate credit is given, any changes made indicated, and the use is non-commercial. See: http://creativecommons.org/licenses/by-nc/4.0/.

\section{ORCID iD}

Stefan Reinders http://orcid.org/0000-0002-8929-6797

\section{REFERENCES}

1 John Hopkins University. COVID-19 Dashboard by the center for systems science and engineering (CSSE) at Johns Hopkins University (JHU), 2020. Available: https://coronavirus.jhu.edu/map. html

2 Blavatnik School of Government. Oxford COVID-19 government response Tracker, 2020. Available: https://www.bsg.ox.ac.uk/ research/research-projects/coronavirus-government-responsetracker

3 AFP News Agency. Evidence is mounting that social distancing successfully slowed the \#coronavirus pandemic after more than half of humanity - 4.5 billion people - were confined to their homes, 18 Apr 2020, 2020. Available: https://twitter.com/afp/status/ 1251556097539874818?lang=en

4 Medeiros de Figueiredo A, Daponte Codina A. Impact of lockdown on COVID-19 incidence and mortality in China: an interrupted time series study. [Preprint]. Bull World Health Organ 2020.

5 Tian H, Liu Y, Li Y, et al. An investigation of transmission control measures during the first 50 days of the COVID-19 epidemic in China. Science 2020;368:638-42.

6 Pan A, Liu L, Wang C, et al. Association of public health interventions with the epidemiology of the COVID-19 outbreak in Wuhan, China. JAMA 2020;323:1915-23.

7 Flaxman S, Mishra S, Gandy A, et al. Estimating the effects of non-pharmaceutical interventions on COVID-19 in Europe. Nature 2020;584:257-61.

8 Van Damme W, Dahake R, Delamou A, et al. The COVID-19 pandemic: diverse contexts; different epidemics-how and why? BMJ Glob Health 2020;5:e003098.

9 Dahab M, van Zandvoort K, Flasche S, et al. COVID-19 control in low-income settings and displaced populations: what can realistically be done? Confl Health 2020;14:54.

10 Douglas M, Katikireddi SV, Taulbut M, et al. Mitigating the wider health effects of covid-19 pandemic response. BM 2020;369:m1557

11 Menendez C, Gonzalez R, Donnay F, et al. Avoiding indirect effects of COVID-19 on maternal and child health. Lancet Glob Health 2020;8:e863-4.

12 Barnett-Howell Z, Mushfiq Mobarak A. Should low-income countries impose the same social distancing guidelines as Europe and North America to halt the spread of Covid-19? 2020. Available: https://som. yale.edu/sites/default/files/mushifiq-howell-v2.pdf

13 Mehtar S, Preiser W, Lakhe NA, et al. Limiting the spread of COVID-19 in Africa: one size mitigation strategies do not fit all countries. Lancet Glob Health 2020;8:e881-3.
14 Gobierno del Perú. Decreto Supremo N 044-2020-PCM, 2020. Available: https://cdn.www.gob.pe/uploads/document/file/566448/ DS044-PCM_1864948-2.pdf

15 Gobierno del Perú. Decreto Supremo N 057-2020-PCM, 2020. Available: https://cdn.www.gob.pe/uploads/document/file/574872/ DS_057-2020-PCM.pdf [Accessed 13 Jun 2020].

16 Gobierno del Perú. Perú analiza 9000 pruebas diarias como parte de estrategia para combatir El Covid-19, 2020. Available: https:// www.gob.pe/institucion/minsa/noticias/112153-peru-analiza-9-000pruebas-diarias-como-parte-de-estrategia-para-combatir-el-covid19

17 Worldometer. COVID-19 coronavirus pandemic, 2020. Available: https://www.worldometers.info/coronavirus/

18 Ministerio de Salud Peru (MINSA). Sala Situacional Covid-19 Peru, 2020. Available: https://covid19.minsa.gob.pe/sala situacional.asp

19 La República. Bono de 380 Soles: familias vulnerables recibirán este beneficio desde este jueves, 2020. Available: https://larepublica. pe/economia/2020/03/17/coronavirus-bono-de-s-380-a-familiasvulnerables-se-distribuira-desde-este-jueves-estado-de-emergencia/

20 La República. Trabajadores independientes podrán cobrar bono de 380 Soles desde El 7 de abril, 2020. Available: https://larepublica.pe/ economia/2020/04/04/bono-380-soles-trabajadores-independientespodran-cobrarlo-a-partir-del-martes-7-de-abril-ministerio-detrabajo-atmp/

21 La República. Bono familiar universal: Mañana inicia El pago del subsidio de 760 Soles, 2020. Available: https://larepublica.pe/ economia/2020/05/19/bono-familiar-universal-manana-inicia-elpago-del-subsidio-de-760-soles/

22 La República. Bono rural: Hoy inicia pago del subsidio de 760 Soles, 2020. Available: https://larepublica.pe/economia/2020/05/14/bonorural-hoy-inicia-pago-del-subsidio-de-760-soles/

23 Gobierno Perú. Gobierno reanuda gradual Y progresivamente actividades económicas. Mediante Decreto Supremo Nº 080-2020PCM, 2020. Available: https://www.gob.pe/institucion/produce/ noticias/143672-gobierno-reanuda-gradual-y-progresivamenteactividades-economicas

24 Our World in Data. Peru: coronavirus pandemic, 2020. Available: https://ourworldindata.org/coronavirus/country/peru

25 Fraser B. COVID-19 strains remote regions of Peru. Lancet 2020;395:1684

26 Instituto Nacional de Estadística e Informática (INEI). lii Censo de Comunidades Nativas 2017. Resultados Definitivos. Tomo 1. Instituto Nacional de Estadistica E Informatica. lima, Diciembre de 2018 , 2018. Available: https://www.inei.gob.pe/media/MenuRecursivo/ publicaciones_digitales/Est/Lib1598/TOMO_01.pdf

27 Instituto Nacional de Estadistica e Informatica (INEI). Evolución de la pobreza monetaria 2007-2017. Informe Técnico. lima, 2018. Available: https://www.inei.gob.pe/media/cifras_de_pobreza/ informe tecnico pobreza monetaria 2007-2017.pdf

28 Instituto Nacional de Estadística e Informática (INEI). Perú: Formas de Acceso al Agua Y Saneamiento Básico, 2018. Available: https:// www.inei.gob.pe/media/MenuRecursivo/boletines/boletin_agua_y_ saneamiento.pdf

29 Huicho L, Segura ER, Huayanay-Espinoza CA, et al. Child health and nutrition in Peru within an antipoverty political agenda: a countdown to 2015 country case study. Lancet Glob Health 2016;4:e414-26.

30 Graham WJ, Afolabi B, Benova L, et al. Protecting hard-won gains for mothers and newborns in low-income and middle-income countries in the face of COVID-19: call for a service safety net. BMJ Glob Health 2020;5:e002754.

31 Huicho L, Huayanay-Espinoza CA, Herrera-Perez E, et al. Examining national and district-level trends in neonatal health in Peru through an equity lens: a success story driven by political will and societal advocacy. BMC Public Health 2016;16 Suppl 2:796.

32 Meneses-Navarro S, Freyermuth-Enciso MG, Pelcastre-Villafuerte $\mathrm{BE}$, et al. The challenges facing Indigenous communities in Latin America as they confront the COVID-19 pandemic. Int J Equity Health 2020;19:63.

33 Ministeriod de Salud Peru (MINSA). Direccion General de Epidemiologia. Mortalidad Neonatal en el Perú y sus departamentos 2011 - 2012. Primera edicion Diciembre 2013, 2011. Available: http:// bvs.minsa.gob.pe/local/MINSA/2745.pdf

34 Limaye NP, Blas MM, Alva IE, et al. The Amazon hope: a qualitative and quantitative assessment of a mobile clinic SHIP in the Peruvian Amazon. PLoS One 2018;13:e0196988.

35 Warren J, Fu R, et al. Global neonatal and perinatal mortality: a review and case study for the Loreto Province of Peru. Res Rep Neonatol 2012;2012:103-13.

36 Ministerio de Salud Peru (MINSA). Norma técnica de salud para la atención integral de salud materna. NTS N 105 - MINSA/DGSP.V.01, 2014. Available: http://bvs.minsa.gob.pe/local/minsa/3281.pdf 
37 Gale NK, Heath G, Cameron E, et al. Using the framework method for the analysis of qualitative data in multi-disciplinary health research. BMC Med Res Methodol 2013;13:117.

38 Roberton T, Carter ED, Chou VB, et al. Early estimates of the indirect effects of the COVID-19 pandemic on maternal and child mortality in low-income and middle-income countries: a modelling study. Lancet Glob Health 2020;8:e901-8.

39 Gobierno del Perú. Plataforma Nacional de Datos Abiertos. Casos positivos por COVID-19 - [Ministerio de Salud - MINSA. Fecha de actualización 24 Julio 2020, 2020. Available: https://www. datosabiertos.gob.pe/dataset/casos-positivos-por-covid-19ministerio-de-salud-minsa

40 Mackworth-Young C, Chingono R, Mavodza C. 'Here, we cannot practice what is preached': early qualitative learning from community perspectives on Zimbabwe's response to COVID-19. [Preprint]. Bull World Health Organ 2020.

41 Coetzee Bronwyné Jo'sean, Kagee A. Structural barriers to adhering to health behaviours in the context of the COVID-19 crisis: considerations for low- and middle-income countries. Glob Public Health 2020;15:1093-102.

42 Asociacion Interetnica de Desarrollo de la Selva Peruana (AIDESEP). Acciones para un plan de emergencia Covid19 en La amazonía indígena, 2020. Available: http://aidesep.org.pe/sites/default/files/ media/noticia/Carta\%20AIDESEP\%207.4.20.pdf

43 El Diario. Perú interviene Los mercados al descubrir cientos de vendedores Con COVID-19, 2020. Available: https://www.eldiario. es/sociedad/Peru-interviene-descubrir-vendedores-COVID-19_0_ 1027497310.html

44 The Guardian. Hubs of infection': how Covid-19 spread through Latin America's markets, 2020. Available: https://www.theguardian. com/world/2020/may/17/coronavirus-latin-america-markets-mexicobrazil-peru

45 Livingston E, Desai A, Berkwits M. Sourcing personal protective equipment during the COVID-19 pandemic. JAMA 2020;323:1912.

46 World Health Organization (WHO). Coronavirus disease 2019 (COVID-19) situation report - 73, 2020. Available: https://www.who. int/docs/default-source/coronaviruse/situation-reports/20200402sitrep-73-covid-19.pdf
47 World Health Organization (WHO). Advice on the use of masks in the context of COVID-19: interim guidance, 2020. Available: https:// www.who.int/publications/i/item/advice-on-the-use-of-masks-inthe-community-during-home-care-and-in-healthcare-settings-in-thecontext-of-the-novel-coronavirus-(2019-ncov)-outbreak

48 Ministerio de Salud Peru (MINSA). Resolución Ministerial. No 2062017/MINSA. Guía Técnica para La continuidad de Los servicios de salud sexual $Y$ reproductiva en situaciones de emergencia y/o desastres en El sector de salud. lima, 2017. Available: http://bvs. minsa.gob.pe/local/MINSA/4632.pdf

49 Sochas L, Channon AA, Nam S. Counting indirect crisis-related deaths in the context of a low-resilience health system: the case of maternal and neonatal health during the Ebola epidemic in Sierra Leone. Health Policy Plan 2017;32:iii32-9.

50 Stein D, Ward K, Cantelmo C. Estimating the potential impact of COVID-19 on mothers and newborns in low- and middle-income countries, 15 April 2020. Health Policy Plus [Blog], 2020. Available: https://medium.com/@HealthPolicyPlus/estimating-the-potentialimpact-of-covid-19-on-mothers-and-newborns-in-low-and-middleincome-3a7887e4a0ff

51 Semaan A, Audet C, Huysmans E, et al. Voices from the frontline: findings from a thematic analysis of a rapid online global survey of maternal and newborn health professionals facing the COVID-19 pandemic. BMJ Glob Health 2020;5:e002967.

52 World Health Organization (WHO), United Nations Population Fund (UNFPA), United Nations Children's Fund (UNICEF). Continuing essential sexual, reproductive, maternal, neonatal, child and adolescent health services during COVID-19 pandemic. operational guidance for South and south-east Asia and Pacific regions. practical considerations, 2020. Available: https://apps.who.int/iris/handle/ 10665/332162

53 Kaplan HS, Trumble BC, Stieglitz J, et al. Voluntary collective isolation as a best response to COVID-19 for Indigenous populations? A case study and protocol from the Bolivian Amazon. Lancet 2020;395:1727-34.

54 Ballard M, Bancroft E, Nesbit J, et al. Prioritising the role of community health workers in the COVID-19 response. BMJ Glob Health 2020;5:e002550. 